\title{
Is Age or Surgical Approach Associated With Osteonecrosis in Patients With Developmental Dysplasia of the Hip? A Meta-analysis
}

\author{
Eduardo N. Novais MD, Mary K. Hill BA, Patrick M. Carry BA, \\ Patricia C. Heyn MS, PhD
}

Published online: 15 October 2015

(C) The Association of Bone and Joint Surgeons ( 2015

\begin{abstract}
Background Osteonecrosis of the femoral head is a major complication that negatively impacts the clinical and radiographic long-term outcome after treatment of developmental hip dysplasia (DDH). There are conflicting results in the literature whether age at the time of closed or open reduction and a specific surgical approach are associated with osteonecrosis. Better understanding of the impact of age at reduction and surgical approach is important to reduce the risk of osteonecrosis in patients with DDH.

Questions/purposes We aimed to evaluate the association between occurrence of osteonecrosis and (1) age at closed reduction; (2) age at open reduction; and (3) medial versus anterior operative approaches.
\end{abstract}

Each author certifies that he or she has no commercial associations (eg, consultancies, stock ownership, equity interest, patent/licensing arrangements, etc) that might pose a conflict of interest in connection with the submitted article.

All ICMJE Conflict of Interest Forms for authors and Clinical Orthopaedics and Related Research ${ }^{\mathbb{R}}$ editors and board members are on file with the publication and can be viewed on request.

Each author certifies that his or her institution approved or waived approval for the human protocol for this investigation and that all investigations were conducted in conformity with ethical principles of research.

This study was conducted at Children's Hospital Colorado, Aurora, CO, USA.

E. N. Novais ( $₫)$, M. K. Hill, P. M. Carry

Department of Orthopaedic Surgery, Children's Hospital

Colorado, 13123 East 17th Avenue, B600, Aurora, CO 80045,

USA

e-mail: eduardo.novais@childrenscolorado.org

P. C. Heyn

Department of Physical Medicine \& Rehabilitation, University

of Colorado School of Medicine, Denver, CO, USA
Methods A systematic review identified studies reporting osteonecrosis occurrence after treatment of DDH and at least 2 years of followup. This study was conducted in accordance with the Preferred Reporting Items for Systematic Reviews and Meta-Analyses statement. Methodologic quality was assessed using the methodologic index for nonrandomized studies. Generalized logistic models were used to estimate pooled odds ratios (ORs) in the meta-analysis. Sixty-six studies were included in the systematic review and 24 in the meta-analysis. Data on 481 hips treated by closed reduction and 584 hips treated by open reduction were available to evaluate the association between osteonecrosis and age. The association between osteonecrosis and operative approach was assessed using data on 364 hips treated by medial open reduction and 220 hips treated by anterior open reduction.

Results Age at reduction $(>12$ months versus $\leq 12$ months) was not associated with osteonecrosis after closed reduction $(\mathrm{OR}, 1.1 ; 95 \%$ confidence interval [CI], 0.4-3.2; $\mathrm{p}=0.9)$ or open reduction $(\mathrm{OR}, 1.1 ; 95 \% \mathrm{CI}, 0.7-1.9 ; \mathrm{p}=$ 0.66). The overall, adjusted incidence of osteonecrosis ( $\geq$ Grade II) was $8.0 \%$ (95\% CI, 2.8\%-20.6\%) among patients treated with closed reduction at or before 12 months of age and $8.4 \%(95 \%$ CI, 3.0\%-21.5\%) among those treated after 12 months. Similarly, the odds of osteonecrosis after open reduction did not differ between patients treated after the age of 12 months compared with those treated at or before 12 months (OR, 1.1; 95\% CI, 0.7-1.9; $\mathrm{p}=0.7$ ). The incidence of osteonecrosis ( $\geq$ Grade II) was $18.3 \%$ (95\% CI, $11.7 \%-27.4 \%$ ) among patients who had index open reduction at or before 12 months of age and $20.0 \%(95 \%$ CI, $13.1 \%-29.4 \%$ ) among those who had index open reduction after 12 months of age. Among hips treated with open reductions, there was no difference in osteonecrosis after medial versus anterior approaches (18.7\% medial 
versus $19.6 \%$ anterior; OR, $1.1 ; 95 \% \mathrm{CI}, 0.5-2.2 ; \mathrm{p}=0.9)$. Conclusions We did not find an association between closed or open reduction performed at or before 12 months of age and an increased risk of osteonecrosis of the femoral head. Delayed treatment past 1 year of age as a strategy to reduce the development of osteonecrosis was not supported by this meta-analysis. Open reduction through a medial or anterior approach may be recommended based on surgeon's preference, because we found no association between development of osteonecrosis and the type of surgical approach. However, many of the studies in the current literature are nonrandomized Level III or IV observational studies of inconsistent quality. Higher quality evidence is needed to better understand the effects of age at reduction and operative approach on the development of osteonecrosis after DDH treatment.

Level of Evidence Level III, therapeutic study.

\section{Introduction}

The most common and serious complication after treatment for developmental dysplasia of the hip (DDH) is osteonecrosis of the femoral head. Osteonecrosis involves compromise of the epiphysis blood supply with frequent ensuing collapse of the articular surface and residual deformity of the hip [44, 90]. Diagnosis and treatment are hindered by a substantial interval between initial obstruction of the vascular supply and onset of discernible radiographic anomalies [17]. Osteonecrosis has been reported to compromise acetabular development after hip reduction and is associated with poor long-term clinical, functional, and radiographic outcomes [30, 42, 69, 71, 91].

The goal of DDH treatment is to obtain concentric hip reduction and allow for acetabular and femoral remodelling with the lowest rate of osteonecrosis as possible. Several factors related to treatment have been postulated to affect the rate of osteonecrosis [35]; however, controversy remains about the safest age to perform a closed or open reduction. Although a previous study reported a low rate of osteonecrosis after closed reduction in the first 3 months of life [76], others reported a more severe pattern of osteonecrosis when closed reduction was performed before 6 months of age [42, 50]. The same is true for DDH treatment by open reduction. Although a correlation between increased age at reduction and osteonecrosis has been reported [49, 55, 56, 62, 65], others have found no such association $[4,5,11,27,95]$.

Further controversy surrounds the choice of a medial versus anterior approach for open reduction of DDH. The medial operative approach was first described by Ludloff [51] and later modified by Ferguson [26] and Weinstein and Ponseti [92] who preferred the term anteromedial approach. Critics of the medial techniques cite an increased risk of osteonecrosis with reported rates reaching 67\% [43]. Although such risk often is attributed to accidental damage of the medial femoral circumflex artery, it is unclear whether injury to this vessel causes osteonecrosis [28, 56]. Conclusions regarding the effectiveness of anterior versus medial operative approaches have been hindered by a lack of studies that directly compare osteonecrosis rates.

Using systematic review and meta-analysis methods, the primary objectives of our study were to assess: (1) the association between age at closed reduction and osteonecrosis occurrence; (2) the association between age at open reduction and osteonecrosis occurrence; and (3) whether the medial or the anterior surgical approach to open reduction is associated with a higher risk of osteonecrosis.

\section{Patients and Methods}

This systematic review and meta-analysis was conducted in accordance with the Preferred Reporting Items for Systematic Reviews and Meta-Analyses statement [60]. An a priori protocol was adhered to throughout the review process to minimize risk of bias.

\section{Search Strategy and Criteria}

A comprehensive search of the PubMed bibliographic database was performed to retrieve articles published from January 1946 to February 17, 2014. Medical librarians with expertise in bibliometric methods were consulted before development and implementation of search criteria, which consisted of index terms and free text based on variations of two key terms: (1) hip dislocation and (2) reduction (Table 1). Search parameters were restricted to English language studies of pediatric populations. Additional searches were conducted of the reference lists of all articles included in the systematic review. References were managed using EndNote(R) X5 software (Thomson Reuters, New York, NY, USA). One reviewer (MKH) screened all identified records for eligibility. Studies included in the qualitative analysis were peer-reviewed, primary data articles that reported treatment-specific osteonecrosis rates (or enough information to calculate such rates) for all eligible subjects after index reduction of idiopathic DDH. In an effort to increase the quality of the selected papers, gray literature was not included. Index reduction was defined as the first open reduction before osteonecrosis occurrence, 
Table 1. PubMed bibliographic database search strategy

\begin{tabular}{|c|c|c|}
\hline $\begin{array}{l}\text { Search } \\
\text { number }\end{array}$ & Search strategy & $\begin{array}{l}\text { Number of } \\
\text { records }\end{array}$ \\
\hline 1 & $\begin{array}{l}\text { "Hip Dislocation, Congenital”[Mesh] OR } \\
\text { "Hip Dislocation"[Mesh] OR (hip[Text } \\
\text { Word] AND ((dislocation[Text Word]) } \\
\text { OR dysplasia[Text Word])) }\end{array}$ & 15584 \\
\hline 2 & reduction[Text Word] & 815814 \\
\hline 3 & $\begin{array}{l}\text { "Child" [Mesh] OR “Infant”[Mesh] OR } \\
\text { (((child*[Text Word]) OR infan*[Text } \\
\text { Word]) OR (pediatric*[Text Word]) OR } \\
\text { paediatric*[Text Word] })\end{array}$ & 2359000 \\
\hline 4 & 1 AND 2 AND 3 & 1017 \\
\hline 5 & Search 4 Filters: English & 770 \\
\hline
\end{tabular}

the first closed reduction before osteonecrosis occurrence if there were no previous or subsequent attempts at open reduction, or the first closed reduction if osteonecrosis developed before subsequent attempts at open reduction. For the purposes of this review, closed reduction constituted nonoperative hip manipulation done with or without adductor tenotomy while the patient was under general anesthesia. Consistent with a previous review [32], studies were required to report on a total of at least 10 eligible hips. To account for a reasonable minimum delay between reduction and the onset of osteonecrosis, studies that reported minimum followups of less than 2 years were excluded. Additionally, studies including patients who underwent open reduction with concomitant pelvic osteotomy and/or patients with teratologic dislocations or neuromuscular disorders were excluded unless data were presented separately for all subjects of interest. Studies were reviewed thoroughly to exclude duplicate data on the same patients. The eligibility of all included studies was confirmed by a second reviewer (ENN).

Conflicting viewpoints surround classification of temporary ossification of the epiphysis as osteonecrosis. Although some classify it as a form of Grade I osteonecrosis [9, 49, 81], others do not consider it osteonecrosis [13, 20, 30, 41, 56, 63, 72, 85, 96]. Because of such variability, osteonecrosis was defined as radiographic changes of Grade II or greater in the meta-analysis. To be included in the open reduction quantitative analysis, studies were required to contribute sample sizes of at least 10 hips to the open treatment group. They also had to report osteonecrosis occurrence ( $\geq$ Grade II) for all eligible subjects specific to age at index reduction (12 months or younger versus older than 12 months) and index operative approach (medial versus anterior). Additionally, to be included in the closed reduction quantitative analysis, studies had to contribute sample sizes of at least 10 hips to the closed treatment group and report osteonecrosis occurrence ( $\geq$ Grade II) for all eligible subjects specific to age at index reduction (12 months or younger versus older than 12 months).

\section{Data Extraction}

A standardized, pilot-tested form was developed based on the guidelines of the Cochrane Handbook for Systematic Reviews of Interventions [37] to collect relevant data pertaining to study design, publication year, treatment details, outcome measures, statistical analyses, results, and osteonecrosis occurrence. When the presence but not pattern of osteonecrosis was reported, the incidence of Grade II or greater osteonecrosis could not be recorded. Age at reduction was collected as a dichotomous variable (12 months or younger versus older than 12 months). Completed data forms were transferred to a Microsoft Excel spreadsheet (Microsoft Inc, Redmond, WA, USA). Data extraction was completed by one reviewer (MKH) and verified by a second (ENN). Primary authors were contacted as necessary to clarify or validate data.

\section{Critical Review}

Levels of evidence for all included studies were established independently and in duplicate by two assessors (MKH, AW) using guidelines of the Oxford Centre for EvidenceBased Medicine adapted for use in orthopaedic journals by The Journal of Bone and Joint Surgery [93]. The methodologic index for nonrandomized studies (MINORS) [78] was independently used in duplicate by two unblinded assessors (MKW, AW) in deriving methodologic quality scores for included studies. MINORS consists of 12 scored items, eight of which pertain to all nonrandomized study types and four of which are specifically relevant to comparative studies. Each index item was appraised on a 3-point scale with 0 assigned to items not reported, 1 assigned to items reported but inadequately, and 2 assigned to items reported adequately. The quality scoring of studies was directly proportional to their methodologic strength with a maximum possible score of 16 for noncomparative studies and 24 for comparative studies. We used the upper cutoff points of 10 for noncomparative studies and 16 for comparative studies to stratify poor versus good quality as suggested by the author of the MINORS scale (email communication, K. Slim MD, FACS; November 2012). In instances of scoring differences, consensus was achieved through discussion. 


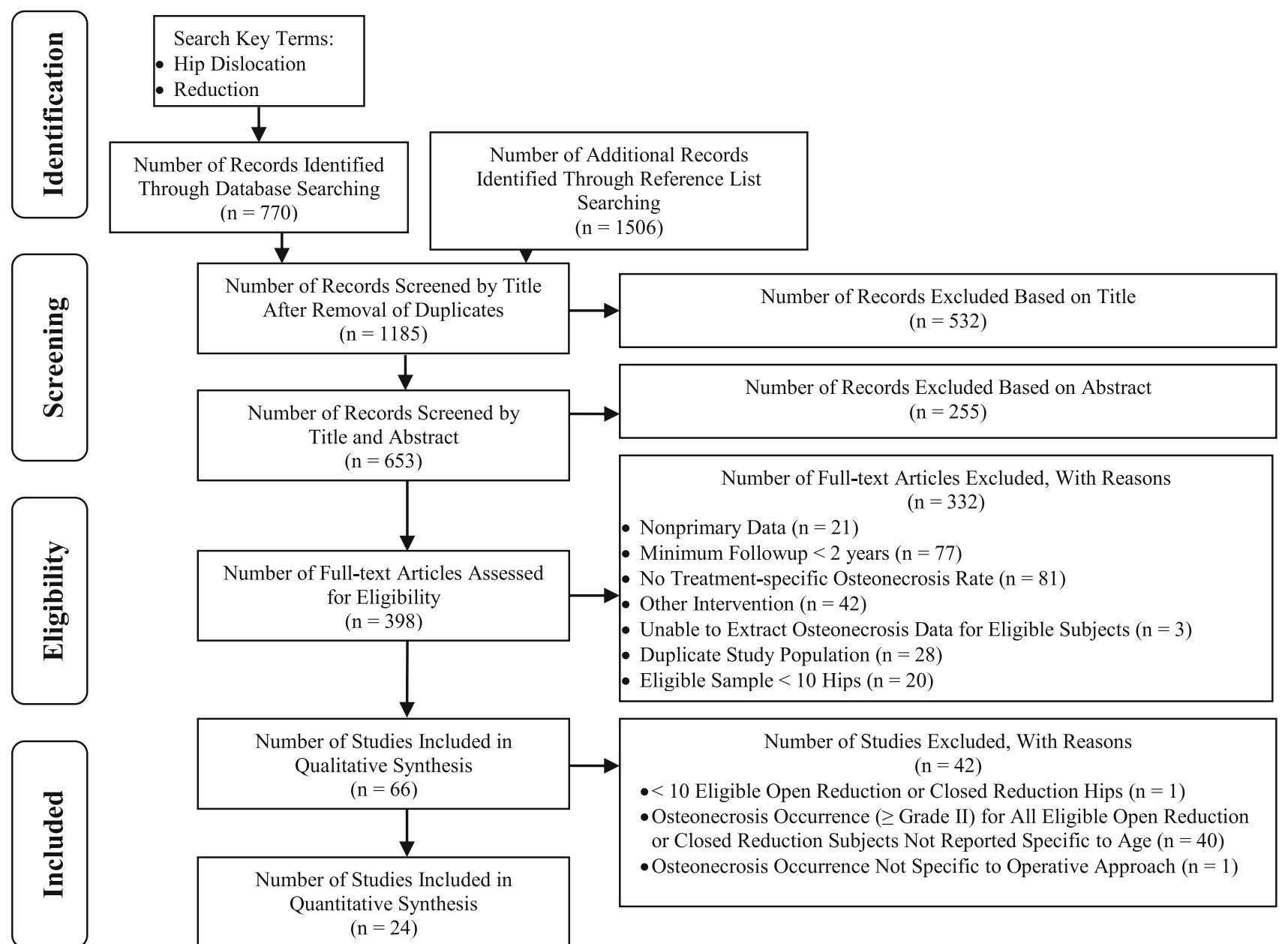

Fig. 1 The search process is illustrated using a modified version of the Preferred Reporting Items for Systematic Reviews and Meta-Analyses flow diagram [60].

\section{Study Selection}

A total of 2276 records (770 from database searching [Table 1] and 1506 from reference lists) were identified (Fig. 1). After removal of duplicate citations, 1185 records were screened, and 787 were excluded based on title and abstract. The resulting 398 full-text articles were retrieved and assessed for eligibility. Of the 332 full texts excluded, 21 were reviews or commentaries; 77 had insufficient followup; 81 did not report treatment-specific osteonecrosis rates; 42 were studies of ineligible interventions; 63 did not report osteonecrosis data for subjects of interest separately from those having undergone open reduction with concomitant pelvic osteotomy and/or those with teratologic dislocations or neuromuscular disorders; 28 were duplicate reports of patient cohorts with any nonduplicate patient data unable to be separately extracted; and 20 reported on fewer than 10 total eligible subjects.

Of the 66 studies included in the systematic review, 24 $[2,4,8,14,21,25,29,31,33,39,41,43,45,48,49,59,62$,
63, 87-89, 94-96] were eligible for meta-analysis (Fig. 1). Of the 42 studies excluded, one [85] did not have at least 10 eligible hips for the open or closed reduction treatment groups. Thirty studies did not report osteonecrosis occurrence for all patients eligible for open or closed reduction specific to age at index reduction (12 months or younger versus older than 12 months). Ten studies $[11,15,19,20$, $24,38,40,64,67,74]$ reported the age-specific occurrence of Grade I or greater osteonecrosis but not Grade II or greater osteonecrosis. One additional study [46] reported osteonecrosis occurrence by age at index open reduction but not by operative approach (medial versus anterior) and was excluded from the meta-analysis.

\section{Study Characteristics}

The 66 reviewed studies were conducted in a total of 19 countries. Of the 49 therapeutic-type [93] studies, one had a level of evidence of II (prospective comparative study) 
[16], seven were Level III (retrospective comparative studies) [5, 13, 38, 54, 57, 61, 94], and 41 were Level IV (case series) [2, 7-11, 15, 20, 23, 24, 27, 30, 31, 34, 39-41, $43,45,46,48,49,56,58,59,62-67,72,80,82,84,85,87-$ $89,95,96]$. There were 16 prognostic studies, of which one was Level I (high-quality prospective study) [19], seven were Level II (retrospective comparative studies) [4, 14, 18, 21, 25, 53, 79], three were Level III (case-control studies) [69, 77, 81], and five were Level IV (case series) [1, 29, 33, 74, 83]. One study was diagnostic Level IV (poor reference standard study) [6]. Methodologic quality was rated as good in $30(45 \%)$ of the reviewed studies and poor in $36(55 \%)$

Working email addresses were available to contact the authors of 27 studies [4-6, 8, 9, 13, 18, 21, 33, 34, 40, 41, 53, 54, 56, 62, 63, 67, 77, 79, 80, 82, 84, 85, 87, 88, 96]. Additional subject-level data were provided by the authors of five studies [33, 62, 63, 79, 87]. If discrepancies were noted between published data and raw data provided by authors, the raw data were recorded.

The 66 reviewed studies reported on a total of 4820 hips. Sufficient subject-level data were available to exclude the following ineligible cases: four dislocations of the hip secondary to neuromuscular or teratologic causes [15, 67], 188 hips treated by open reduction with concomitant pelvic osteotomy [8, 10, 19, 20, 29, 31, 33, 38, 46, 59, 69, 74, 95, $96]$, and 280 hips treated by other ineligible interventions [23, 64, 85, 94]. Additionally, one study [13] included 12 hips treated by medial open reduction that at least partly overlapped with a more recently published article [49]. Subject-level data for the 12 hips were not available on request, and therefore we excluded the entire study subset to avoid inclusion of duplicate data. Data for the remaining 4336 hips were included in the descriptive synthesis.

Thirty-nine studies $[1,4,6-8,11,13,14,16,18-20,23$, 27, 29, 30, 34, 38, 40, 41, 45, 53, 54, 56, 61, 64, 67, 69, 72, $74,77,79,81,83-85,89,94,96]$ reported on a total of 2548 eligible hips managed by index closed reduction. A total of 1788 eligible cases of index open reductions were reported in 50 studies, of which 19 [2, 7, 10, 13, 16, 21, 24, $27,31,33,39,59,61,64,66,82,84,89,96]$ reported an anterior operative approach, 18 [1, 4-6, 9, 15, 25, 43, 48, $49,54,58,63,65,80,87,88,95]$ reported a medial approach, eight [19, 41, 53, 56, 57, 62, 69, 85] examined anterior and medial approaches, and five [23, 29, 46, 67, 74] did not report the index operative approach(es). Reported age protocols for patients having open treatment type included use of a medial operative approach for patients who were younger than 12 months [69], 13 months or younger [54], older than 6 months [5], between 6 and 18 months old [95], younger than 18 months [43], and younger than 24 months [87]; an anterior approach for patients 12 months or older [57, 69]; and no operative treatment at all before 9 months of age [7].

Assessments of osteonecrosis were made using, often in combination, the criteria of Bucholz and Ogden [12] in 14 studies [7, 13, 14, 31, 34, 38, 43, 49, 53, 62, 69, 77, 79, 80], Kalamchi and MacEwen [42] in 24 studies [1, 2, 5, 9, 16, 18, 19, 21, 25, 27, 29, 43, 46, 48, 59, 65, 82, 83, 85, 87-89, 94, 95], Salter et al. [72] in 23 studies [8-11, 13, 15, 19, 29, 30, 33, 38-41, 53, 54, 56, 57, 61, 64, 72, 81, 96], Gage and Winter [30] in five studies [11, 29, 30, 41, 67], and Tönnis [86] in one study [6]. Ten studies [4, 20, 23, 24, 45, 58, 63, $66,74,84]$ did not report the criteria used to assess osteonecrosis.

Sixteen studies $[1,4,5,11,14,27,49,53,56,61,62,65$, 69, 88, 94, 95] statistically analyzed the relationship between age at reduction and the occurrence of osteonecrosis. The analyses of five studies [56, 62, 69, 94, 95] were based partly on data that did not reflect our definition of index reduction. Significance levels were not published in three studies [14, 27, 61] and were reported as 0.05 in all other reviewed studies. When all grades of osteonecrosis were analyzed, 10 studies [1, 4, 27, 53, 61, $68,69,88,94,95]$ found no statistically significant associations between age and osteonecrosis incidence. One study [56] found no difference in osteonecrosis occurrence when comparing medial open reduction performed during the first versus second year of life, but did find an association between total osteonecrosis incidence and age using chi square analysis. Another study [49] found the average age at medial open reduction to be significantly older for patients who had osteonecrosis develop than for patients who did not have osteonecrosis develop. Additionally, one study [62] found osteonecrosis occurrence increased with age in a comparison of subjects operatively treated 12 months old or younger, 13 to 24 months old, and older than 24 months old. When analyzing only Grade II or greater osteonecrosis, three studies [5, 14, 53] found no statistically significant relationship between age at reduction and osteonecrosis incidence, whereas one study [65] found average age at medial open reduction to be significantly older for patients who had osteonecrosis develop than for those who did not. None of the 66 reviewed studies statistically analyzed the relationship between operative approach (medial versus anterior) and osteonecrosis occurrence.

Our meta-analysis included nine studies (481 hips) [4, 8, $14,29,41,45,89,94,96]$ in the closed reduction model and 16 (584 hips) [2, 21, 25, 31, 33, 39, 43, 48, 49, 59, 62, $63,87-89,95]$ in the open reduction model. Eleven $(46 \%)$ of the analyzed studies were rated as being of good methodologic quality and $13(54 \%)$ as poor. The crude incidence of osteonecrosis ( $\geq$ Grade II) was $6.9 \%$ (33 of 

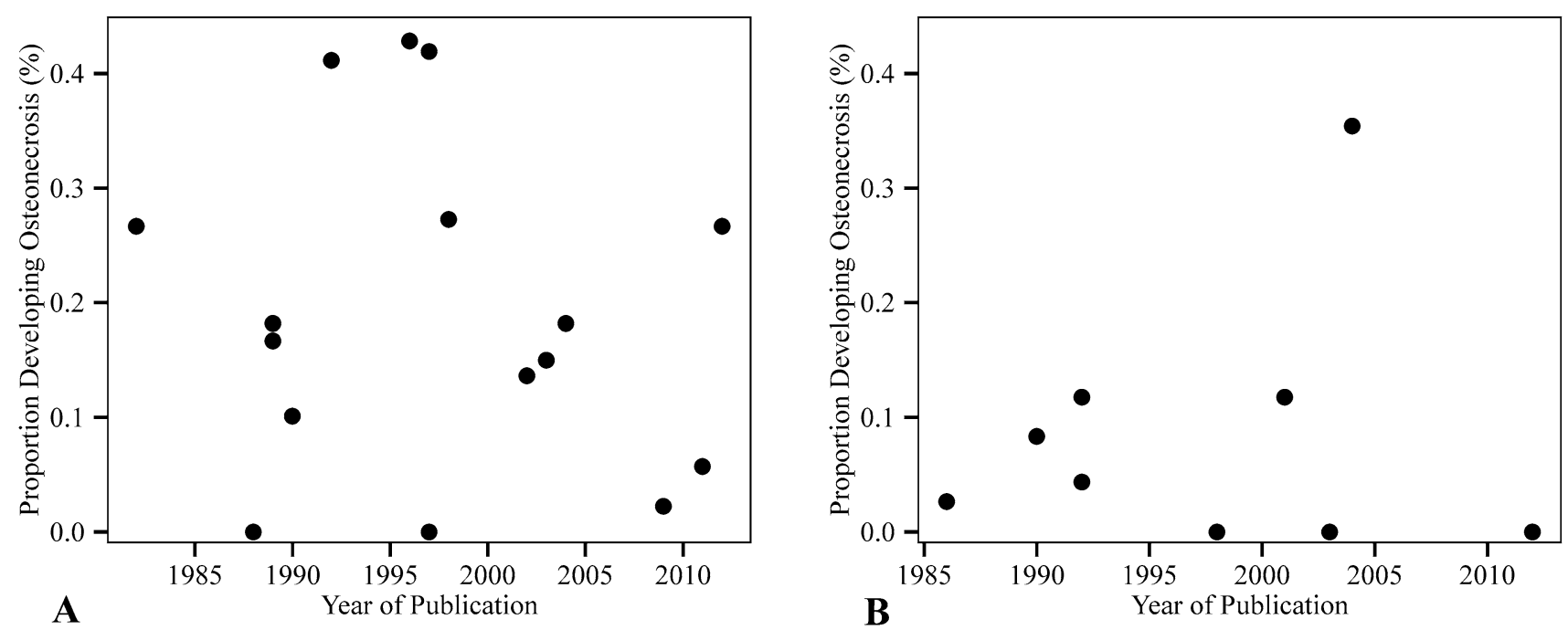

Fig. 2A-B The funnel plots show the relationship between publication year and crude osteonecrosis rate by (A) open and (B) closed reduction.

481 hips) after index closed reduction and 19.9\% (116 of 584 hips) after index open reduction. In the open reduction model, nine studies [25, 43, 48, 49, 62, 63, 87, 88, 95] reported an index medial approach was used in 364 eligible hips and eight studies [2, 21, 31, 33, 39, 59, 62, 89] reported an index anterior approach was used in 220 eligible hips.

\section{Statistical Methods}

Crude osteonecrosis incidence estimates were summarized using descriptive statistics. Odds ratios (ORs) with $95 \%$ confidence intervals (CIs) were calculated using generalized multivariable logistic regression models. Generalized estimating equations were used to account for the clustering effect of subjects in studies. An interaction term was included in the open reduction model to test whether the association between age and the occurrence of osteonecrosis was significantly dependent on operative approach (medial versus anterior). During the modelbuilding step of the analysis, funnel plots of the relationship between publication year and crude osteonecrosis rates as well as sample size were reviewed to assess publication year and study sample size as potential confounding variables (publication bias). The plots did not reveal any discernible time or sample size dependent trends (Figs. 2, 3). The alpha level was set at 0.05.

For the closed reduction analysis, the model had $80 \%$ power to detect a difference of $29 \%$ in osteonecrosis occurrence among subjects who underwent closed reduction $>12$ months versus $\leq 12$ months of age (OR, 7.5). Using the crude data, this calculation assumed the within- study correlation was 0.13 , the occurrence of osteonecrosis in the reference group ( $\leq 12$ months) was $7 \%$, and the ratio of subjects in the two age groups was 3:2. For the open reduction analysis, our study had $80 \%$ power to detect a difference of $27 \%$ in osteonecrosis occurrence among subjects who underwent open reduction at $>12$ months versus $\leq 12$ months of age $(\mathrm{OR}, 3.8)$. Using the crude data, this calculation assumed the within-study correlation was 0.15 , the occurrence of osteonecrosis in the reference group ( $\leq 12$ months) was $17 \%$, and the ratio of subjects in the two age groups was 1:1.

\section{Results}

The odds of osteonecrosis developing after closed reduction did not differ between patients whose hips were first reduced after the age of 12 months compared with those treated at or before 12 months (OR, 1.1; 95\% CI, 0.4-3.2; $\mathrm{p}=0.9)$. The overall, adjusted incidence of osteonecrosis ( $\geq$ Grade II) was $8.0 \%$ (95\% CI, 2.8\%-20.6\%) among patients who underwent index closed reduction at or before 12 months of age and 8.4\% (95\% CI, 3.0\%-21.5\%) among those who had index closed reduction after 12 months.

Likewise, the odds of osteonecrosis developing after open reduction did not differ between patients whose hips were first reduced after the age of 12 months compared with those treated at or before 12 months (OR, 1.1; 95\% CI, $0.7-1.9 ; \mathrm{p}=0.7)$. Based on the multivariable generalized logistic regression analysis, there was no difference $(\mathrm{p}=$ 0.2 ) in the relationship between age at open reduction and the occurrence of osteonecrosis between patients who underwent a medial versus anterior operative approach 

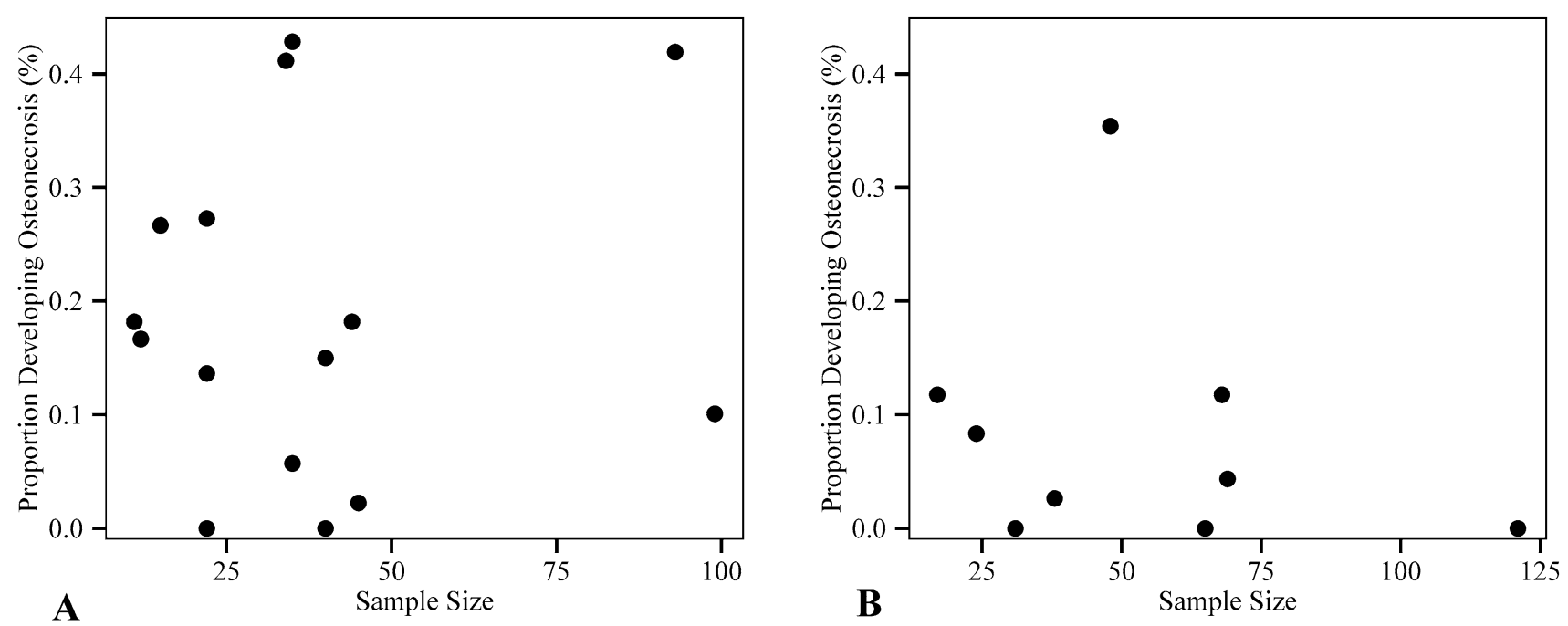

Fig. 3A-B The funnel plots show the relationship between sample size and crude osteonecrosis rate by (A) open and (B) closed reduction.

(age*treatment interaction). This indicates that the relationship between age and osteonecrosis occurrence did not depend on open reduction approach used. After controlling for operative approach (medial versus anterior), the incidence of osteonecrosis ( $\geq$ Grade II) was $18.3 \%$ (95\% CI, $11.7 \%-27.4 \%$ ) among patients who had index open reduction at or before 12 months of age and $20.0 \%$ (95\% CI, 13.1\%-29.4\%) among those who had index open reduction after 12 months of age.

Finally, we found no difference in the risk of osteonecrosis between the medial and the anterior approaches (OR, 1.1; 95\% CI, 0.5-2.2; p = 0.9). After controlling for age at reduction, the incidence of osteonecrosis ( $\geq$ Grade II) after index open reduction was $18.7 \%$ (95\% CI, $11.0 \%-30.0 \%$ ) for patients treated using a medial operative approach and $19.6 \%$ (95\% CI, 12.4\%$29.5 \%$ ) for those who had an anterior approach.

\section{Discussion}

Osteonecrosis is the most devastating complication after treatment of $\mathrm{DDH}$, which compromises acetabular remodeling and negatively impacts the long-term hip function and radiographic results. Although dozens of papers have evaluated age at the time of hip reduction and surgical approach as potential predictors of the development of osteonecrosis after treatment for DDH, there is substantial disagreement among them. Better understanding of the association of age at reduction and osteonecrosis is crucial to elucidate whether early versus planned delayed closed or open reduction should be performed for the treatment of a dislocated hip, especially after failure of conservative treatment with a Pavlik harness or other brace. For hips requiring open reduction, achieving concentric reduction and avoiding osteonecrosis have been shown to be the main factors in accomplishing the best long-term hip functional and radiographic results [32, 42, 52, 72, 92]. However, there is still controversy whether the anterior or the medial approach is the safest strategy to accomplish the lowest rate of osteonecrosis. Therefore, we designed a systematic review and a meta-analysis study to investigate the association between occurrence of osteonecrosis and (1) age at closed reduction; (2) age at open reduction; and (3) medial versus anterior operative approaches.

This study has several limitations. First our findings are based on the results of observational studies, because this was the only type of available evidence. Given the observational nature of the included studies and lack of uniformly available raw data, we were unable to account for all potential confounding variables such as failure of previous treatment, associated procedures including adductor tenotomy, length of immobilization, and degree of abduction in a spica cast. In addition, the degree of dysplasia was not consistently reported in most of the studies, which could lead to bias in comparison of different severity types of DDH. However, we attempted to reduce the influence of residual confounding by adjusting the variance for the clustering effect of subjects in studies. Second, when stratifying the meta-analysis data by groupings of younger than versus older than 12 months of age at reduction, we were able to definitively conclude that hips reduced in patients at exactly 12 months old were included in the former category in all but four studies [8, $39,41,89]$. Although the presence and stratification of 12month-old patients in these studies was less evident, we 
believe any potential discrepancies were minimal. Therefore, we believe the inclusion of these studies in the metaanalysis was warranted. Third, 55\% of the reviewed studies and $54 \%$ of studies included in the meta-analysis were rated as being of poor methodologic quality. Although we acknowledge the importance of individual study quality to our findings, we made no adjustments for quality differences because it has been suggested that weighting or excluding studies from meta-analysis based on quality scoring is futile [36]. Fourth, we acknowledge that the literature may have an inherent bias of publication and we did not include in our study a search of the gray literature that would include unpublished data. However, our methodology was followed as a strict protocol in accordance with the Preferred the Preferred Reporting Items for Systematic Reviews and Meta-Analyses statement [60]. Finally, there was potential for assessor bias, because reviewers rating methodologic quality of the studies were not blinded. We attempted to control for this by having two reviewers (MKH, AW), including one external assessor (AW), perform quality assessments independently and in duplicate.

This meta-analysis found no difference in the odds of having osteonecrosis ( $\geq$ Grade II) develop when closed reduction was performed in patients 12 months or younger versus patients older than 12 months. In scrutinizing our findings, an important clinical practice question remains unanswered. In a patient with a dislocated hip presenting during the first year of life with or without a history of previous treatment failure, what is the safest age with lower rates of osteonecrosis to attempt a closed reduction? Senaran et al. [76] reported a low rate of osteonecrosis in patients with DDH who failed Pavlik harness treatment and underwent prompt reduction within 3 months of age. In contrast, a more severe pattern of osteonecrosis when reduction is performed before 6 months of age has been reported [42, 50]. Segal et al. [75] studied 49 patients (57 hips) who were younger than 12 months of age at reduction (closed and open) with 18 hips complicated by osteonecrosis. They recommended delaying treatment until the ossification of the femoral head is present on radiographs. Based on our findings, delaying closed reduction past 12 months of age should not be recommended, because there was no association with reduced rates of osteonecrosis. Future comparative studies will be key in determining whether procrastinating treatment negatively impacts the ability to achieve a concentric stable reduction by closed means and to elucidate the association between age at closed reduction and development of osteonecrosis.

In the quantitative analysis, there was no difference in the odds of Grade II or greater osteonecrosis when open reduction was performed in patients 12 months or younger versus patients older than 12 months. In contrast, in a recent systematic review of medial open reduction, Gardner et al. [32] reported a higher rate of osteonecrosis in patients younger than 12 months. Contrary to our strict definition of index reduction, their analysis did not specify whether the age data were based on first and/or subsequent attempts at open reduction. They also included studies [15, 47] with subjects without idiopathic DDH who were ineligible for our review. The controversy about the association between age at open reduction and osteonecrosis remains. Previous studies proposing delaying the treatment of DDH hypothesized that the development of the microcirculation in the femoral head, concomitant with the radiographic appearance of the ossific nucleus, would protect against osteonecrosis [16, 75]. However, other studies [21, 53, 70] did not find older age and the presence of ossific nucleus as protective factors for osteonecrosis. Those opposing delaying treatment would further ague that it could potentially compromise acetabular remodeling, whereas early reduction may prompt better development of a congruent hip [22]. Most studies [16, 21, 52, 53] agree that the older the child the more likely further surgery to correct residual acetabular dysplasia will be necessary. Well-designed comparative studies of similar patients with DDH will help clarify whether age at open reduction is associated with osteonecrosis and whether early intervention indeed allows for better remodeling and is associated with lower rate of reoperations compared with delayed intervention.

We found no difference in the odds of osteonecrosis developing after anterior versus medial open reduction after adjusting for age at reduction. Despite various hypotheses regarding the superiority of each operative technique, none of the 66 reviewed studies included in our systematic review directly compared anterior versus medial osteonecrosis incidences using statistical procedures. In addition, this meta-analysis compared observational studies reporting results of anterior and open reduction without associated femoral shortening osteotomy that has been reported to relatively protect against osteonecrosis $[31,73]$. The rate of osteonecrosis after medial open reduction in our study was similar to the rate reported by Gardner et al. [32]. In general, anterior open reduction has been the preferred approach for patients older than 24 months of age, whereas most authors restrict the indication of medial reduction for patients younger than 24 months of age [15, 49, 56, 62, 65, 92]. Therefore, the most relevant clinical question that remains to be answered is as follows. What is the safest (lowest rate of osteonecrosis) surgical approach in patients who require an open reduction during the first 24 months of life? We believe that a randomized clinical trial with adequate control for cofounding variables is needed to answer this question. Long-term studies evaluating patients at skeletally maturity age will be necessary to assess 
another important outcome in DDH treatment, which is the need for further additional surgeries to correct residual hip dysplasia after these two approaches.

The goals of treatment for a dislocated hip secondary to DDH are to achieve concentric reduction with the lowest rate of osteonecrosis because this complication has been reported to negatively impact further development of the joint and the clinical and radiographic long-term outcomes [91]. Our meta-analysis found that closed and open reduction before or after a patient is 1 year old and the type of operative approach did not appear to be associated with an increased risk of osteonecrosis. However, during our systematic review we found that there is no universally accepted classification system for assessing the severity and prognosis of osteonecrosis. To determine predictive factors of osteonecrosis and guide treatment and prognosis, it would be necessary that different centers investigating this problem collect similar data and use a consistent and reproducible classification system. In addition, long-term followup studies would be optimal, because the rate of osteonecrosis has been reported to increase with the length of followup [3, 32, 88].

The majority of the studies including in this metaanalysis were rated as being of poor methodologic quality. We also noted a lack of uniform collection of data in the studies evaluated in our review. Therefore, we strongly recommend that future studies investigating DDH and osteonecrosis consistently report patient-specific factors (age, gender, weight, laterality, family history), the presence or absence of the ossific nucleus of the femoral head on radiographs or ultrasound as well as baseline severity of hip dysplasia. If authors prefer to report age as a categorical variable, we recommend it to be uniformly stratified by 6-month interval during the first 2 years of life ( 0 to $\leq 6$ months, 6 to $\leq 12$ months; 12 to $\leq 18$ months and 18 to $\leq$ 24 months and $>24$ months). In addition, treatment-related variables should be systematically reported, including use of preoperative traction and previous failure of Pavlik or other bracing treatment. Concomitant procedures performed during the index reduction such as adductor and iliopsoas tenotomy, femoral shortening, and pelvic osteotomies and the degree of abduction and length of spica cast immobilization and bracing should also be consistently noted. The results of well-designed, prospective controlled trials will be required to elucidate the association between age at closed and open reduction and type of surgical approach (anterior versus medial) and osteonecrosis of the femoral head after treatment of DDH.

Acknowledgments We thank Adrienne Wood BA (Department of Physical Medicine \& Rehabilitation, University of Colorado School of Medicine), for contributions to the critical review; Zhaoxing Pan $\mathrm{MB}, \mathrm{PhD}$ (Research Institute, Children's Hospital Colorado), for assistance with statistical planning; and Paul Blomquist MLS (Health
Sciences Library, University of Colorado Denver), and Marie St Pierre MLIS (Clinical and Research Library, Children's Hospital Colorado), for consultation on the search strategy.

\section{References}

1. Agus H, Omeroglu H, Ucar H, Bicimoglu A, Turmer Y. Evaluation of the risk factors of avascular necrosis of the femoral head in developmental dysplasia of the hip in infants younger than 18 months of age. J Pediatr Orthop B. 2002;11:41-46.

2. Akagi S, Tanabe T, Ogawa R. Acetabular development after open reduction for developmental dislocation of the hip. 15-year follow-up of 22 hips without additional surgery. Acta Orthop Scand. 1998;69:17-20.

3. Akilapa O. The medial approach open reduction for developmental dysplasia of the hip: do the long-term outcomes validate this approach? A systematic review of the literature. J Child Orthop. 2014;8:387-397.

4. Alsiddiky AM, Bakarman KA, Alzain KO, Aljassir FF, AlAhaideb AS, Kremli MK, Zamzam MM, Mervyn Letts R. The early detection and management of unstable concentric closed reduction of DDH with percutaneous K-wire fixation in infants 6 to 12 months of age. J Pediatr Orthop. 2012;32:64-69.

5. Altay M, Demirkale I, Senturk F, Firat A, Kapicioglu S. Results of medial open reduction of developmental dysplasia of the hip with regard to walking age. J Pediatr Orthop B. 2012;22:36-41.

6. Ando M, Gotoh E, Matsuura J. Tangential view arthrogram at closed reduction in congenital dislocation of the hip. $J$ Pediatr Orthop. 1992;12:390-395.

7. Angliss R, Fujii G, Pickvance E, Wainwright AM, Benson MK. Surgical treatment of late developmental displacement of the hip. Results after 33 years. J Bone Joint Surg Br. 2005;87:384-394.

8. Arac S, Bozkurt M, Kiter E, Gunal I. Medial approach without opening the joint capsule for developmental dislocation of the hip. J Orthop Sci. 2003;8:522-525.

9. Bache CE, Graham HK, Dickens DR, Donnan L, Johnson MB, Nattrass G, O'Sullivan M, Torode IP. Ligamentum teres tenodesis in medial approach open reduction for developmental dislocation of the hip. J Pediatr Orthop. 2008;28:607-613.

10. Berkeley ME, Dickson JH, Cain TE, Donovan MM. Surgical therapy for congenital dislocation of the hip in patients who are twelve to thirty-six months old. J Bone Joint Surg Am. 1984;66:412-420.

11. Brougham DI, Broughton NS, Cole WG, Menelaus MB. Avascular necrosis following closed reduction of congenital dislocation of the hip. Review of influencing factors and longterm follow-up. J Bone Joint Surg Br. 1990;72:557-562.

12. Bucholz R, Ogden J. Patterns of ischemic necrosis of the proximal femur in nonoperatively treated congenital hip disease. The Hip. Proceedings of the Sixth Open Scientific Meeting of the Hip Society. St Louis, MO, USA: CV Mosby: 1978:43-63.

13. Camp J, Herring JA, Dworezynski C. Comparison of inpatient and outpatient traction in developmental dislocation of the hip. $J$ Pediatr Orthop. 1994;14:9-12.

14. Carney BT, Clark D, Minter CL. Is the absence of the ossific nucleus prognostic for avascular necrosis after closed reduction of developmental dysplasia of the hip? J Surg Orthop Adv. 2004;13:24-29.

15. Castillo R, Sherman FC. Medial adductor open reduction for congenital dislocation of the hip. J Pediatr Orthop. 1990;10:335-340.

16. Clarke NM, Jowett AJ, Parker L. The surgical treatment of established congenital dislocation of the hip: results of surgery after planned delayed intervention following the appearance of the capital femoral ossific nucleus. $J$ Pediatr Orthop. 2005;25:434-439. 
17. Connolly P, Weinstein SL. [The course and treatment of avascular necrosis of the femoral head in developmental dysplasia of the hip] [in Turkish]. Acta Orthop Traumatol Turc. 2007;41(Suppl 1):54-59.

18. Cooke SJ, Rees R, Edwards DL, Kiely NT, Evans GA. Ossification of the femoral head at closed reduction for developmental dysplasia of the hip and its influence on the long-term outcome. $J$ Pediatr Orthop B. 2010;19:22-26.

19. Danielsson L. Late-diagnosed DDH: a prospective 11-year follow-up of 71 consecutive patients (75 hips). Acta Orthop Scand. 2000;71:232-242.

20. Daoud A, Saighi-Bououina A. Congenital dislocation of the hip in the older child. The effectiveness of overhead traction. J Bone Joint Surg Am. 1996;78:30-40.

21. Dhar S, Taylor JF, Jones WA, Owen R. Early open reduction for congenital dislocation of the hip. J Bone Joint Surg Br. 1990;72:175-180.

22. Diméglio A, Kaelin A, Bonnel F, Rosa VD, Couture A. The growing hip: specifications and requirements. J Pediatr Orthop B. 1994;3:135-147.

23. Dooley BJ. Osteochondritis in congenital dislocation and subluxation of the hip. J Bone Joint Surg Br. 1964;46:198-203.

24. Doudoulakis JK, Cavadias A. Open reduction of CDH before one year of age. 69 hips followed for 13 (10-19) years. Acta Orthop Scand. 1993;64:188-192.

25. Erturk C, Altay MA, Yarimpapuc R, Isikan UE. Medial open reduction of developmental dysplasia of the hip using the Weinstein-Ponseti approach. Saudi Med J. 2011;32:901-906.

26. Ferguson AB Jr. Primary open reduction of congenital dislocation of the hip using a median adductor approach. J Bone Joint Surg Am. 1973;55:671-689.

27. Firth GB, Robertson AJ, Schepers A, Fatti L. Developmental dysplasia of the hip: open reduction as a risk factor for substantial osteonecrosis. Clin Orthop Relat Res. 2010;468:2485-2494.

28. Fisher EH 3rd, Beck PA, Hoffer MM. Necrosis of the capital femoral epiphysis and medial approaches to the hip in piglets. $J$ Orthop Res. 1991;9:203-208.

29. Forlin E, Choi IH, Guille JT, Bowen JR, Glutting J. Prognostic factors in congenital dislocation of the hip treated with closed reduction. The importance of arthrographic evaluation. $J$ Bone Joint Surg Am. 1992;74:1140-1152.

30. Gage JR, Winter RB. Avascular necrosis of the capital femoral epiphysis as a complication of closed reduction of congenital dislocation of the hip. A critical review of twenty years' experience at Gillette Children's Hospital. J Bone Joint Surg Am. 1972;54:373-388.

31. Galpin RD, Roach JW, Wenger DR, Herring JA, Birch JG. Onestage treatment of congenital dislocation of the hip in older children, including femoral shortening. J Bone Joint Surg Am. 1989;71:734-741.

32. Gardner RO, Bradley CS, Howard A, Narayanan UG, Wedge JH, Kelley SP. The incidence of avascular necrosis and the radiographic outcome following medial open reduction in children with developmental dysplasia of the hip: a systematic review. Bone Joint J. 2014;96:279-286.

33. Gholve PA, Flynn JM, Garner MR, Millis MB, Kim YJ. Predictors for secondary procedures in walking DDH. $J$ Pediatr Orthop. 2012;32:282-289.

34. Gogus MT, Aksoy MC, Atay OA, Acaroglu RE, Surat A. Treatment of congenital dislocation of the hip. Results of closed reduction and immobilization in the hip spica cast. Turk $J$ Pediatr. 1997;39:499-503.

35. Gregosiewicz A, Wosko I. Risk factors of avascular necrosis in the treatment of congenital dislocation of the hip. J Pediatr Orthop. 1988;8:17-19.
36. Herbison P, Hay-Smith J, Gillespie WJ. Adjustment of metaanalyses on the basis of quality scores should be abandoned. $J$ Clin Epidemiol. 2006;59:1249-1256.

37. Higgins JPT, Green SE. Cochrane Handbook for Systematic Reviews of Interventions Version 5.1. 0 [updated March 2011]. The Cochrane Collaboration. 2011. Available at: http://www. cochrane-handbook.org. Assessed August 5, 2012.

38. Huang SC, Wang JH. A comparative study of nonoperative versus operative treatment of developmental dysplasia of the hip in patients of walking age. J Pediatr Orthop. 1997;17:181-188.

39. Ikegami K, Nakatsuka Y, Akazawa H, Mitani S, Inoue H. Deformity of the proximal end of the femur following open reduction for developmental dislocation of the hip. Acta Med Okayama. 1997;51:39-44.

40. Ishii Y, Ponseti IV. Long-term results of closed reduction of complete congenital dislocation of the hip in children under one year of age. Clin Orthop Relat Res. 1978;137:167-174.

41. Kahle WK, Anderson MB, Alpert J, Stevens PM, Coleman SS. The value of preliminary traction in the treatment of congenital dislocation of the hip. J Bone Joint Surg Am. 1990;72:1043-1047.

42. Kalamchi A, MacEwen GD. Avascular necrosis following treatment of congenital dislocation of the hip. J Bone Joint Surg Am. 1980;62:876-888.

43. Kalamchi A, Schmidt TL, MacEwen GD. Congenital dislocation of the hip. Open reduction by the medial approach. Clin Orthop Relat Res. 1982;169:127-132.

44. Kaushik AP, Das A, Cui Q. Osteonecrosis of the femoral head: an update in year 2012. World J Orthop. 2012;3:49-57.

45. Kerry RM, Simonds GW. Long-term results of late non-operative reduction of developmental dysplasia of the hip. J Bone Joint Surg Br. 1998;80:78-82.

46. Kershaw CJ, Ware HE, Pattinson R, Fixsen JA. Revision of failed open reduction of congenital dislocation of the hip. J Bone Joint Surg Br. 1993;75:744-749.

47. Kiely N, Younis U, Day JB, Meadows TM. The ferguson medial approach for open reduction of developmental dysplasia of the hip. A clinical and radiological review of 49 hips. J Bone Joint Surg Br. 2004;86:430-433.

48. Koizumi W, Moriya H, Tsuchiya K, Takeuchi T, Kamegaya M, Akita T. Ludloff's medial approach for open reduction of congenital dislocation of the hip. A 20-year follow-up. J Bone Joint Surg Br. 1996;78:924-929.

49. Konigsberg DE, Karol LA, Colby S, O'Brien S. Results of medial open reduction of the hip in infants with developmental dislocation of the hip. J Pediatr Orthop. 2003;23:1-9.

50. Kruczynski J. Avascular necrosis of the proximal femur in developmental dislocation of the hip. Incidence, risk factors, sequelae and MR imaging for diagnosis and prognosis. Acta Orthop Scand Suppl. 1996;268:1-48.

51. Ludloff $\mathrm{K}$. The open reduction of the congenital hip dislocation by an anterior incision. Am J Orthop Surg. 1913;10:438-454.

52. Luhmann SJ, Bassett GS, Gordon JE, Schootman M, Schoenecker PL. Reduction of a dislocation of the hip due to developmental dysplasia. Implications for the need for future surgery. $J$ Bone Joint Surg Am. 2003;85:239-243.

53. Luhmann SJ, Schoenecker PL, Anderson AM, Bassett GS. The prognostic importance of the ossific nucleus in the treatment of congenital dysplasia of the hip. J Bone Joint Surg Am. 1998;80:1719-1727.

54. Madhu TS, Akula M, Scott BW, Templeton PA. Treatment of developmental dislocation of hip: does changing the hip abduction angle in the hip spica affect the rate of avascular necrosis of the femoral head? J Pediatr Orthop B. 2013;22:184-188.

55. Malvitz TA, Weinstein SL. Closed reduction for congenital dysplasia of the hip. Functional and radiographic results after an 
average of thirty years. J Bone Joint Surg Am. 1994;76:17771792.

56. Mankey MG, Arntz GT, Staheli LT. Open reduction through a medial approach for congenital dislocation of the hip. A critical review of the Ludloff approach in sixty-six hips. J Bone Joint Surg Am. 1993;75:1334-1345.

57. Matsushita T, Miyake Y, Akazawa H, Eguchi S, Takahashi Y. Open reduction for congenital dislocation of the hip: comparison of the long-term results of the wide exposure method and Ludloff's method. J Orthop Sci. 1999;4:333-341.

58. Mau H, Dorr WM, Henkel L, Lutsche J. Open reduction of congenital dislocation of the hip by Ludloff's method. $J$ Bone Joint Surg Am. 1971;53:1281-1288.

59. McCluskey WP, Bassett GS, Mora-Garcia G, MacEwen GD. Treatment of failed open reduction for congenital dislocation of the hip. J Pediatr Orthop. 1989;9:633-639.

60. Moher D, Liberati A, Tetzlaff J, Altman DG. Preferred reporting items for systematic reviews and meta-analyses: the PRISMA statement. PLoS Med. 2009;6:e1000097.

61. Molina Guerrero JA, Munuera Martinez L, Esteban Mugica B. Acetabular development in congenital dislocation on the hip. Acta Orthop Belg. 1990;56:293-300.

62. Morcuende JA, Meyer MD, Dolan LA, Weinstein SL. Long-term outcome after open reduction through an anteromedial approach for congenital dislocation of the hip. J Bone Joint Surg Am. 1997;79:810-817.

63. O'Hara JN, Bernard AA, Dwyer NS. Early results of medial approach open reduction in congenital dislocation of the hip: use before walking age. J Pediatr Orthop. 1988;8:288-294.

64. Ohsako H, Sakou T, Matsunaga S. Open reduction and varusdetorsion osteotomy with femoral shortening in treatment of congenital dislocation of the hip. J Orthop Sci. 1998;3:304-309.

65. Okano K, Yamada K, Takahashi K, Enomoto H, Osaki M, Shindo H. Long-term outcome of Ludloff's medial approach for open reduction of developmental dislocation of the hip in relation to the age at operation. Int Orthop. 2009;33:1391-1396.

66. Papavasiliou VA, Papavasiliou AV. Surgical treatment of developmental dysplasia of the hip in the periadolescent period. $J$ Orthop Sci. 2005;10:15-21.

67. Rehm A, Divekar A, Conybeare ME. External fixation for femoral derotation osteotomy in developmental dysplasia of the hip. J Pediatr Orthop B. 2003;12:319-327.

68. Rejholec M, Sosna A, Dupal P. Overhead traction in the treatment of congenital dislocation of the hip. Chir Organi Mov. 1993;78:223-226.

69. Roposch A, Liu LQ, Offiah AC, Wedge JH. Functional outcomes in children with osteonecrosis secondary to treatment of developmental dysplasia of the hip. J Bone Joint Surg Am. 2011;93:e145.

70. Roposch A, Odeh O, Doria AS, Wedge JH. The presence of an ossific nucleus does not protect against osteonecrosis after treatment of developmental dysplasia of the hip. Clin Orthop Relat Res. 2011;469:2838-2845.

71. Roposch A, Ridout D, Protopapa E, Nicolaou N, Gelfer Y. Osteonecrosis complicating developmental dysplasia of the hip compromises subsequent acetabular remodeling. Clin Orthop Relat Res. 2013;471:2318-2326.

72. Salter RB, Kostuik J, Dallas S. Avascular necrosis of the femoral head as a complication of treatment for congenital dislocation of the hip in young children: a clinical and experimental investigation. Can J Surg. 1969;12:44-61.

73. Schoenecker PL, Strecker WB. Congenital dislocation of the hip in children. Comparison of the effects of femoral shortening and of skeletal traction in treatment. J Bone Joint Surg Am. 1984;66:21-27.
74. Schwartz DR. Acetabular development after reduction of congenital dislocation of the hip: a follow-up study of fifty hips. $J$ Bone Joint Surg Am. 1965;47:705-714.

75. Segal LS, Boal DK, Borthwick L, Clark MW, Localio AR, Schwentker EP. Avascular necrosis after treatment of DDH: the protective influence of the ossific nucleus. J Pediatr Orthop. 1999;19:177-184.

76. Senaran H, Bowen JR, Harcke HT. Avascular necrosis rate in early reduction after failed Pavlik harness treatment of developmental dysplasia of the hip. J Pediatr Orthop. 2007;27:192-197.

77. Sibinski M, Synder M. Lateral growth disturbances of the capital femoral epiphysis after nonoperative treatment of late developmental dislocation of the hip: thirty-five cases followed to skeletal maturity. J Pediatr Orthop. 2006;26:307-309.

78. Slim K, Nini E, Forestier D, Kwiatkowski F, Panis Y, Chipponi J. Methodological index for non-randomized studies (minors): development and validation of a new instrument. ANZ J Surg. 2003;73:712-716.

79. Sllamniku S, Bytyqi C, Murtezani A, Haxhija EQ. Correlation between avascular necrosis and the presence of the ossific nucleus when treating developmental dysplasia of the hip. J Child Orthop. 2013;7:501-505.

80. Sosna A, Rejholec M. Ludloff's open reduction of the hip: longterm results. J Pediatr Orthop. 1992;12:603-606.

81. Staheli LT, Dion M, Tuell JI. The effect of the inverted limbus on closed management of congenital hip dislocation. Clin Orthop Relat Res. 1978;137:163-166.

82. Szepesi K, Szucs G, Szeverenyi C, Csernatony Z. Long-term follow-up of DDH patients who underwent open reduction without a postoperative cast. J Pediatr Orthop B. 2013;22:8590.

83. Taketa M, Fujii T, Kubota H, Nakashima Y, Noguchi Y, Iwamoto Y. Correlation between center-edge angle and acetabulum-head index in developmental dysplasia of the hip with avascular necrosis of the femoral head. J Pediatr Orthop B. 2003;12:215218.

84. Tasnavites A, Murray DW, Benson MK. Improvement in acetabular index after reduction of hips with developmental dysplasia. J Bone Joint Surg Br. 1993;75:755-759.

85. Tavares JO, Gottwald DH, Rochelle JR. Guided abduction traction in the treatment of congenital hip dislocation. Journal of pediatric orthopedics. 1994;14:643-649.

86. Tönnis D. An evaluation of conservative and operative methods in the treatment of congenital hip dislocation. Clin Orthop Relat Res. 1976;119:76-88.

87. Trolic Z, Ljubic B, Gavrankapetanovic I, Prlic J, Moro G, Latincic A. Open reduction of congenital hip dislocation by medial approach: case series. Croat Med J. 2002;43:312-318.

88. Ucar DH, Isiklar ZU, Stanitski CL, Kandemir U, Tumer Y. Open reduction through a medial approach in developmental dislocation of the hip: a follow-up study to skeletal maturity. $J$ Pediatr Orthop. 2004;24:493-500.

89. Valdiserri L, Campagnaro JG, Urso R. The treatment of congenital hip dislocation between the ages of 1 and 3. Chir Organi Mov. 1992;77:219-231.

90. Vitale MG, Skaggs DL. Developmental dysplasia of the hip from six months to four years of age. J Am Acad Orthop Surg. 2001;9:401-411.

91. Weinstein SL. Congenital hip dislocation. Long-range problems, residual signs, and symptoms after successful treatment. Clin Orthop Relat Res. 1992;281:69-74.

92. Weinstein SL, Ponseti IV. Congenital dislocation of the hip. $J$ Bone Joint Surg Am. 1979;61:119-124.

93. Wright JG, Swiontkowski MF, Heckman JD. Introducing levels of evidence to the journal. J Bone Joint Surg Am. 2003;85:1-3. 
94. Yoshitaka T, Mitani S, Aoki K, Miyake A, Inoue H. Long-term follow-up of congenital subluxation of the hip. J Pediatr Orthop. 2001;21:474-480.

95. Zamzam MM, Khoshhal KI, Abak AA, Bakarman KA, AlSiddiky AM, AlZain KO, Kremli MK. One-stage bilateral open reduction through a medial approach in developmental dysplasia of the hip. J Bone Joint Surg Br. 2009;91:113-118.

96. Zionts LE, MacEwen GD. Treatment of congenital dislocation of the hip in children between the ages of one and three years. $J$ Bone Joint Surg Am. 1986;68:829-846. 